\title{
Application of Solidification Theory with Small-supercooling to Morphology of Dendritic Inclusions in Steel
}

\author{
Masana IMAGUMBAI and Hiroyuki KAJIOKA ${ }^{11}$ \\ Nippon Steel Technoresearch Corporation, Shintomi, Futtsu, Chiba-ken, 293 Japan. \\ 1) Nippon Steel Corporation, Shintomi, Futtsu, Chiba-ken, 293 Japan.
}

(Received on October 17, 1995; accepted in final form on April 12, 1996)

\begin{abstract}
Tip shape of dendritic Type II manganese-sulfide is analysed based on the supercooling solidification theory which Lipton et al. proposed. The theory is derived from the marginal stability of dendrite tip, and needs several physical parameters and constants which are not necessarily known accurately for manganese-sulfide/enriched melt interface. The authors' approach took rough assessment to the figures of physical properties, but the results of calculation give a confidence to a theoretical method of evaluating tip radius of the inclusions.
\end{abstract}

KEY WORDS: inclusion, solidification, dendrite.

\section{Introduction}

Inclusions in steel have been a chronic concern of metallurgists and engineers treating steel materials. A huge number of experiments and theoretical approaches has been done. Quite a few of these efforts gave a general viewpoint explaining the intrinsic growth mechanism of inclusions. None the less, few of these works applied the modern concept on liquid $\rightarrow$ solid transformation called precipitation, or solidification, although promising theories of solidification have been developed in these couple of decades. ${ }^{1-3}$ )

Precipitation mechanism of inclusions in steel with low melting point is inseparable from solidification process of steel-matrix. As many researchers have emphasized, the precipitation kinetics of inclusions, their morphologies and the site where inclusions precipitate, or, disperse in steel dendrite structures, have to be understood as an inevitable sequence of a cause and consequence. Hence, anyone who intends to get good perspective over these, has to know the sequence. Solidification structure of most killed-steels, whose mechanical properties are significantly affected by sulfide-, or oxide-inclusions, is dendritic. Therefore, it is necessary to elucidate how the inclusions grow and freeze into their final shape, size and dispersion, in co-operation with dendritic microsegregation as well as contraction of residual melt held among steel dendrite arms. Briefly, the essence of the problem here is inquiring into solidifying behavior of inclusions in the residual melt.

The authors' approach basically depends upon the recent theory of solidification with small supercooling. ${ }^{3)}$ It aims to see the applicability of the marginal stability $^{1-5)}$ (Lipton-Glicksman-Kurz theory, or, LGKTrelation) to ( $\mathrm{Mn}-\mathrm{Fe}-\mathrm{S})$ liquid-phase/enriched-melt inter- face in a pool of residual melt, regarding carbon as the solute which plays the crucial role in deciding the interface, and shows that the marginal stability works well in predicting the shape and size of dendritic inclusions than the classical nucleation and growth method. Furthermore, in authors' scope is involved a clue to interpret the generalized hypothesis proposed by Steinmetz and Lindenberg, ${ }^{6-8)}$ who proved the morphological change depends upon local activity balance of constituent elements of an inclusion, regardless of the species.

\section{Theoretical}

\subsection{Background for Applying Supercooling Theory to Precipitation of Inclusions in Residual Melt}

Most elements of steel enrich into residual melt among steel dendrites, and reduce the solidifying temperature of the local melt. It is of primary significance to examine whether this solidifying temperature of residual melt $\left(T_{\mathrm{e}}\right)$ is equal to solidus line of incipient melt in actual solidification condition $\left(T_{\mathrm{LS}}\right)$, or not, when one tries to describe the precipitation behavior of sulfide-, or oxide-inclusion having lower melting point. According to the definition of solidus line of an alloy, it is principally thought 'fraction of solid equals unity', which is solidus, verifies the finish of solidifying of residual melt, i.e., $T_{\mathrm{e}}=T_{\mathrm{LS}}$. The idea should barely be valid, as far as the residual melt threads through the narrower passages among the steel dendrite arms keeping its continuity, or, one thermodynamic treatment upon the solid/liquid interface can be applicable to the whole system. If precipitation occurs in a residual melt which already quit the system, the precipitation reaction of inclusions must be treated as in a different system. Even if precipitation of inclusion takes place in a continuous melt, the pre- 
cipitation temperature $\left(T_{\mathrm{ppt}}\right)$ would be conditioned according to solidification mode of inclusion. In eutectic mode, $T_{\mathrm{ppt}}$ means $T_{\mathrm{e}}$, but in dendritic, $T_{\mathrm{ppt}}$ is higher than $T_{\mathrm{e}}$, provided the reaction occurred in stable state.

Obviously the question here is, however, not in solidification mode of inclusion but in continuity of liquid phase to the very end of steel primary dendrite bottom. For sulfide-inclusions in steel, several experiments ${ }^{9-13}$ ) have been opened. The experiment done by Ito et al. $^{93}$ shows that Type II MnS precipitates at temperature lower than $T_{\mathrm{LS}}$ by about $100^{\circ} \mathrm{C}$. The same drop of temperature was observed by the author's experiment ${ }^{12)}$ which was done with a uni-directional solidification method. The latter also shows steel dendrites fix their final structure at temperature range a little bit lower than $T_{\mathrm{S}}$. It should be noted that the existence of 'not completely solidified small region' existed immediately below $T_{\text {LS }}$. This region remained in minutely separated, and discontinuous from the mass of melt, in the portion $c a .100^{\circ} \mathrm{C}$ below $T_{\mathrm{LS}}$, where the growth of dendritic Type II MnS-inclusions accelerated.

From the result of observation on steel dendrite structure and inclusion's precipitation behavior, the author proposed a model (Solidification Unit Cell model ${ }^{12)}$ ) for sequence of contracion of residual melt as depicted in Fig. 1, accounting for the steel dendrite growth and the morphology deformation of the liaising residual melt. In the model, steel dendrite structure is seemed to conform to truncated octahedra (14-facet polyhedra) stacks, and residual melt is to shrink gradually onto the interface of 14-facet polyhedra. The geometric size is calculated with solidification variables, e.g., $R$ : growth rate of solidification front of steel dendrites and $G$ : temperature gradient along solid/liquid zone. In order to make easy to understand the polyhedra model, the characteristic temperatures relating to solidification are designated to their specified locations as shown in Fig. 1.

In the recent theory the temperature at a primary dendrite tip is thought to be lower than the equilibrium liquidus $\left(T_{\mathrm{L}}\right)$ by a certain amount of supercooling $\left(\Delta T^{*}\right)$, which, in general, is consisted of several kind of different supercooling mechanisms. ${ }^{14}$ ) This means the surface temperature of primary dendrite tip, or the temperature at the tip of solid phase skin contacting to liquid phase, is given as $T_{\mathrm{L}}^{*}\left(=T_{\mathrm{L}}-\Delta T^{*}\right)$.

In a uni-directional solidification experiment ${ }^{12)}$ with aluminum-killed steels of approximately $0.6 \mathrm{C}-0.6 \mathrm{Mn}-$ $0.07 \mathrm{~S}-0.0010$ (mass $\%$ ), secondary or higher dendrite

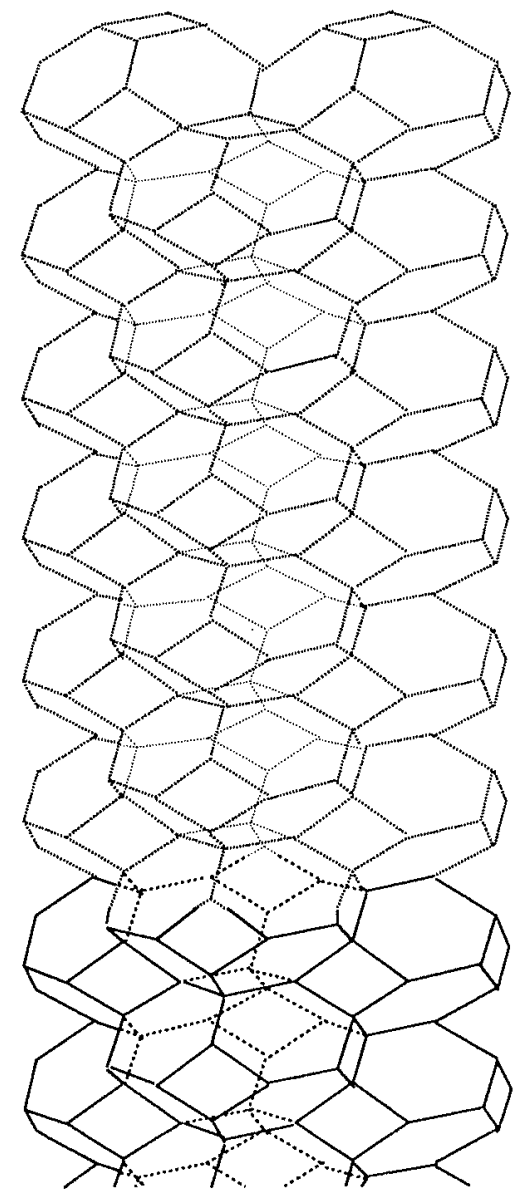

Solidification Unit Cell Model for uni-directional solidification of steel (Ref.12)

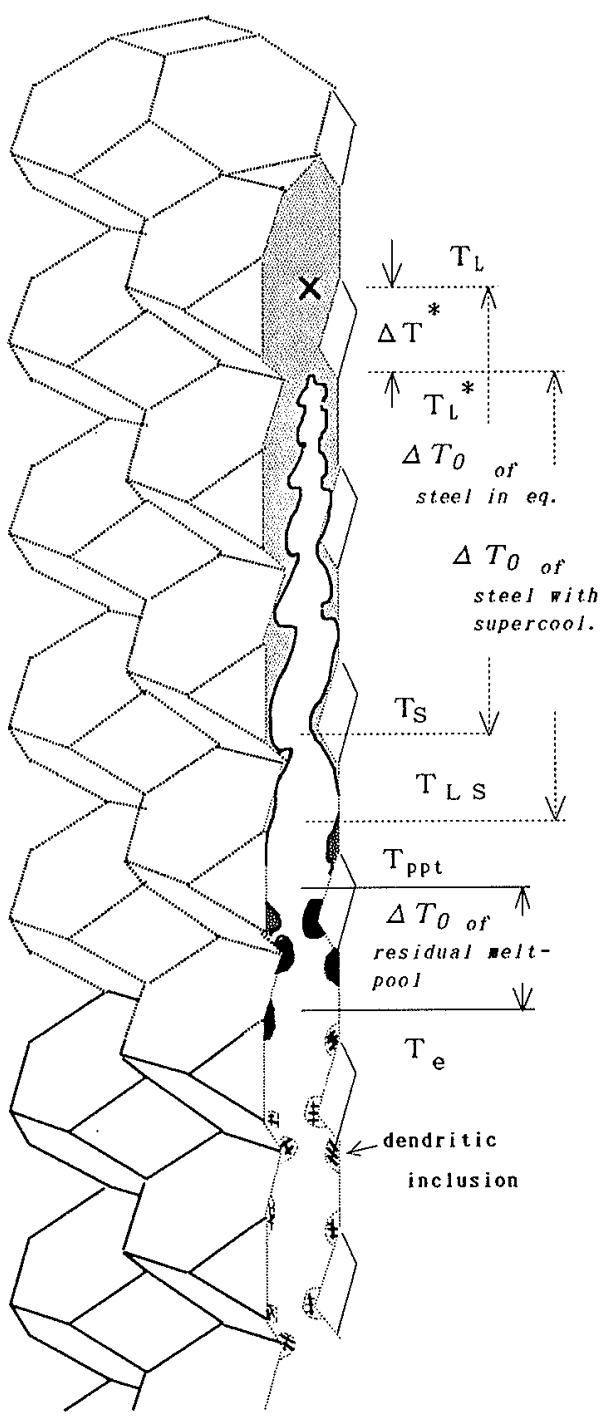

Fig. 1.

Dendrite structure of steel solidified uni-directionally in steady state and a model for solidification behavior of the residual melt-pool(precipitation of dendritic inclusions). 


$$
\begin{array}{lll}
T \sim T_{S} & T \sim T_{L S} & T \sim T_{p p t \rightarrow T_{e}} \\
& f>0.9 & f \sim 0.99
\end{array}
$$
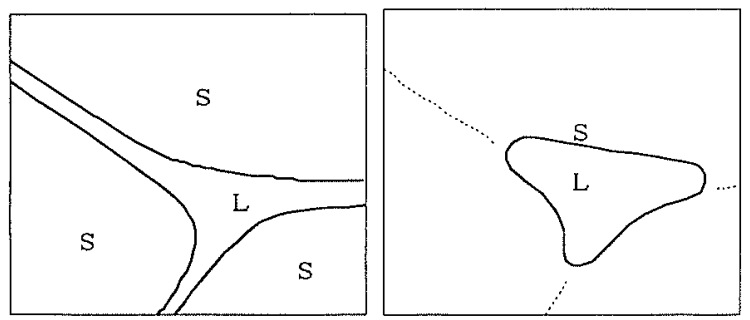

S : Steel dendrite

$S$ : Steel dendrite

$L$ : Liquid phase among $L$ : Enriched melt pool steel dendrite arms

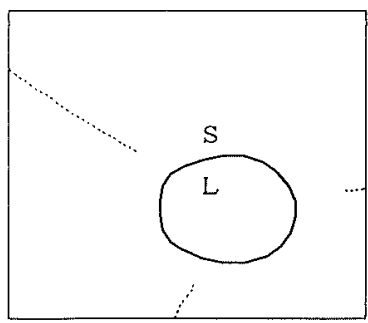

$S$ : Steel dendrite

$L$ : Remnant melt in enriched melt pool
Fig. 2.

Spherical contraction of residual melt among steel dendrite arms toward completion of solidification. arms of the steel start growing at the tip of primary arms until the location whose temperature is estimated to be $T_{\mathrm{LS}}$, which, in this case, is lower than $T_{\mathrm{S}}$ by nearly $100^{\circ} \mathrm{C}$. Down to here, it was thought the residual melt kept continuity onto the interface of the polyhedra. In the experiment, an interesting observation was that dendritic Type II MnS-inclusions grew their arm thickness below $T_{\mathrm{LS}}$, where increase of steel dendrite arm-spacing was no more recognized. Also FeS-inclusion, which absolutely has lower melting point, became coarser at even lower temperatures. From the observation fraction of solid: $f$ at the temperature $T_{\mathrm{LS}}$ was calculated ${ }^{13)}$ as 0.99 . And the areas where these sulfides grew are regarded to correspond to the polyhedron edges.

One more interesting, and essentially very important, result of the experiment is explained as follows. Above $T_{\mathrm{LS}}$ the estimated area of residual melt becomes thinner onto the polyhedra interface as mentioned above, but below it the melt pool becomes to globular, allocated on the polyhedra edge points (Referred to Fig. 4 in Ref. 12) and Fig. 3 in Ref. 13)). This is explained that the surface of solid grown from steel dendrite in contact with the residual melt below $T_{\mathrm{LS}}$ remelts and the melt pool becomes to be rounded and isolated from the melt of mass. All this is illustrated in Fig. 2. The melt pools in Fig. 2 contain high concentration of solutes, in particular, carbon atoms. The enrichment of $\mathrm{C}$ immediately after the solidification completion of residual melt would not be detected, however, because carbon atoms diffuse easily to the surrounding steel matrix during the refrigerating process.

What happened in a residual melt pool between $T_{\mathrm{LS}}$ and $T_{\mathrm{e}}$ could be thought as a supercooling solidification of sulfide inclusion. The supercooling must be small when the overall process proceeds slowly. Somewhere in a pool of residual melt the solidification of sulfide starts, in dendritic or eutectic manner, depending on the activities of $\mathrm{Mn}, \mathrm{S}$ and $\mathrm{O}$ there. ${ }^{7)}$ Carbon concentration in the process plays scarcely any role to the forming of inclusion, except deciding interface between inclusion (carbon atoms are excluded) and remnant melt which is enriched in C-concentration. Figure 3 is an interpretation of dendritic solidification under supercooling.

\subsection{Summary of Lipton-Glicksman-Kurz Theory}

Recent theoretical approach to dendritic solidification

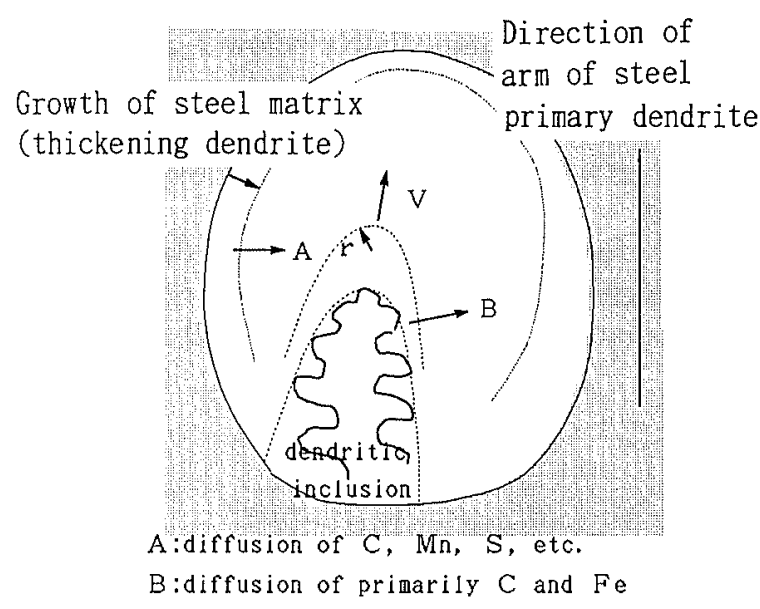

Fig. 3. Dendritic solidification of inclusions in supercooled enriched-melt surrounded by steel matrix.

of binary alloys under supercooling is attempted by applying the marginal stability criterion ${ }^{4)}$ to a classic theoretical model referred to Ivantsov transport solution. ${ }^{15)}$ The calculated prediction are encouraged by experiments. ${ }^{3,16)}$ Radius of primary dendrite tip of inclusions $(r)$ and growth rate of the tip $(V)$ are calculated from the theory. Lipton and other researchers ${ }^{3,5,14}$ introduced a numerical relation to dendritic solidification of binary alloys under small supercooling (hereinafter called as LGKT-relation). The relation between $r$ and $V$ is given with Eq. (1),

$$
r=\frac{\Gamma / \sigma^{*}}{2 P\left(k \Delta T_{\mathrm{o}} / \phi\right) \xi_{\mathrm{C}}+P_{\mathrm{t}}\left\{\left(\Delta H / c_{\mathrm{L}}\right) / \beta\right\} \xi_{\mathrm{L}}}
$$

where $\phi$ is 'Iwantsov function' given as $\left\{1-(1-k) I_{\mathrm{v}}(P)\right\}$, $P$ is solute Péclet number at dendrite tip, $P_{t}$ is thermal Péclet number, and they are given as in Eq. (2), respectively (uncommented marks; referred to Nomenclature).

$$
P=V r / 2 D \quad \text { and } \quad P_{\mathrm{L}}=V r / 2 a_{\mathrm{L}}
$$

The parameter $\sigma^{*}$ relates to dendrite tip shape and is given $^{1,4)}$ for a stable tip theoretically as $\sigma^{*}=1 / 4 \pi^{2}$. The experiment by Huang et $a l^{16)}$ gave slightly smaller value though, the constant $1 / 4 \pi^{2}(\sim 0.025)$ is generally accepted. The parameter $\xi_{\mathrm{C}}$ is a function of solute Péclet number and can be deemed as unity, if $V$ is small or the solidification is under small supercooling. Also $\xi_{L}$, which 
is a function of thermal Péclet number in liquid side, is unity for small supercooling. The parameter $\beta=\{1+$ $\left.\left(K_{\mathrm{S}} / K_{\mathrm{L}}\right)^{2}\right\} / 2$ is again unity, if thermal conductivity in solid: $K_{\mathrm{S}}$ is nearly equal to that in liquid: $K_{\mathrm{L}}$. Provided above approximations are allowed, Eq. (1) is simplified to Eq. (3).

$$
V r^{2} \sim \frac{40 \Gamma}{k \Delta T_{0} / D \phi+\Delta H /\left(2 a_{\mathrm{L}} c_{\mathrm{L}}\right)}
$$

Equation (3) is rewritten to Eq. (4) by using Eqs. (2).

$$
r=\frac{40 \Gamma / P_{\mathrm{t}}}{2 a_{\mathrm{L}} k \Delta T_{\mathrm{o}} / D \phi+\Delta H / c_{\mathrm{L}}}
$$

\section{Analysis}

\subsection{Summary of the Results of Experiment Submitted to the Present Analysis}

Table 1 is the reproduced data ${ }^{12)}$ of a series of uni-directional solidification experiments. Two steels were used in the experiments, steel a: $0.62 \mathrm{C}-0.12 \mathrm{Si}-$ $0.58 \mathrm{Mn}-0.006 \mathrm{P}-0.073 \mathrm{~S}-0.049 \mathrm{Al}-0.0011 \mathrm{O}$, and steel $\mathrm{b}$ : $0.52 \mathrm{C}-0.10 \mathrm{Si}-0.56 \mathrm{Mn}-0.003 \mathrm{P}-0.046 \mathrm{~S}-0.037 \mathrm{Al}-0.0011 \mathrm{O}$ (in mass \%). Each run of uni-directional solidification was controlled under the given solidification conditions. The sample was quenched and behaviors of sulfideinclusions were observed. Particular attention was paid to find the relationship between the change in dendrite structure of steel and the evolution of growth of inclu-

Table 1. Experimental result of uni-directional solidification in which relationship between $V_{\text {suc }}$ of steel and $d_{\mathrm{MnS}}$ of $\mathrm{MnS}$-inclusion was obtained, details refer to Ref. 12).

\begin{tabular}{rcccclcc}
\hline Test & & \multicolumn{3}{c}{ Solid. variables } & & & $\begin{array}{c}\text { Rod } \\
\text { No. }\end{array}$ \\
\cline { 3 - 4 } & & $\begin{array}{c}R \\
(\mu \mathrm{m} / \mathrm{s})\end{array}$ & $\begin{array}{c}G \\
(\mathrm{~K} / \mathrm{mm})\end{array}$ & $\begin{array}{c}V_{\text {suc }} \\
\left(\mathrm{mm}^{3}\right)\end{array}$ & $\begin{array}{c}\text { Morphology } \\
\text { of MnS }\end{array}$ & $\begin{array}{c}\text { diameter } \\
d_{\text {Mns }} \\
(\mu \mathrm{m})\end{array}$ \\
\hline 9 & $\mathrm{a}$ & 28.7 & 1.99 & 0.27 & dendritic Type II & 7.8 \\
5 & $\mathrm{a}$ & 56.2 & 1.81 & 0.18 & dendritic Type II & 6.8 \\
3 & $\mathrm{a}$ & 28.8 & 4.81 & 0.066 & dendritic Type II & 4.4 \\
11 & $\mathrm{a}$ & 21.8 & 16.3 & 0.015 & dendritic Type II & 4.2 \\
12 & $\mathrm{~b}$ & 5.28 & 2.04 & 0.41 & dendritic Type II & 9.4 \\
13 & $\mathrm{~b}$ & 4.97 & 4.83 & 0.16 & dendritic Type II & 8.0 \\
17 & $\mathrm{~b}$ & 4.12 & 10.9 & 0.056 & dendritic Type II & 5.6 \\
\hline
\end{tabular}

sion. The data in Table 1 are obtained at the portion of specimen where all the gradual changes had already finished at the quenching, i.e., morphology and size of inclusions in the observed area are thought to be fixed before the quenching. $V_{\text {suc }}$ in Table 1 is a characteristic size of steel dendrite structure which can be given ${ }^{12)}$ if solidification variables are known. The detailed explanation and additional information on the experiments are given in the other publications. ${ }^{12,13)}$

\subsection{Analysis by LGKT-relation}

In applying the LGKT-relation to the data in Table1, we need several physical constants and equilibrium data of an enriched chemical composition of the residual melt. The authors regard the solidifying residual melt as a pseudo-binary system of $(\mathrm{Fe}-\mathrm{Mn}-\mathrm{S})-(\mathrm{Fe}-\mathrm{C})$ which is interpreted conceptually in Fig. 4. The primary phase in Fig. 4 corresponds to sulfide $\left(\mathrm{Mn}_{x} \mathrm{Fe}_{1-x} \mathrm{~S}\right)$ and the enriched one, to the remnant liquid in the final pool of the residual melt, which is illustrated in Fig. 3. Exact composition of the former shall be obtained in other publications, ${ }^{18-24)}$ whereby a numerical calculation is needed to know how far the composition of liquid phase which transforms to sulfide-inclusion follows a topological path in $\mathrm{Fe}-\mathrm{Mn}-\mathrm{S}$ phase diagram, in another words, to what extent the enrichment of sulfur goes on among steel dendrites. Another information we need is the carbon concentration in the remnant melt at the moment when the melt solidifies, or the temperature of the melt reached $T_{\mathrm{ppt}}$ (higher than $T_{\mathrm{e}}$, for dendritic inclusions).

Physical properties used in calculations are shown in Table 2. In the calculations we posturated the equilibrium value $\left(\Delta T_{0}\right)$ as approximately $10^{2} \mathrm{C}$. The meaning of

Table 2. Physical property for supercooled solidification of sulfide in residual melt-pool.

\begin{tabular}{llcl}
\hline Symbol & Unit & \multicolumn{1}{c}{ Value } & \multicolumn{1}{c}{ Literatures } \\
\hline$\Gamma$ & $\mathrm{K} \cdot \mathrm{m}$ & $\sim 10^{-7}$ & (generally presumed) \\
$a_{\mathrm{L}}$ & $\mathrm{m}^{2} / \mathrm{s}$ & $3.7 \times 10^{-6}$ & Ref. 26) \\
$k$ & - & $\sim 0.3$ & (Fe-C equilibrium diagram) \\
$\Delta T_{0}$ & $\mathrm{~K}$ & $\sim 10^{2}$ & \\
$D$ & $\mathrm{~m}^{2} / \mathrm{s}$ & $2.4 \times 10^{-9}$ & Refs. 25), 26) \\
$\phi$ & - & $\sim 1$ & Ref. 5) \\
$\Delta H$ & $\mathrm{~J} / \mathrm{m}^{3}$ & $1.9 \times 10^{9}$ & Ref. 26) \\
$c_{\mathrm{L}}$ & $\mathrm{J} / \mathrm{K} / \mathrm{m}^{3}$ & $5.9 \times 10^{6}$ & Ref. 26) \\
\hline
\end{tabular}

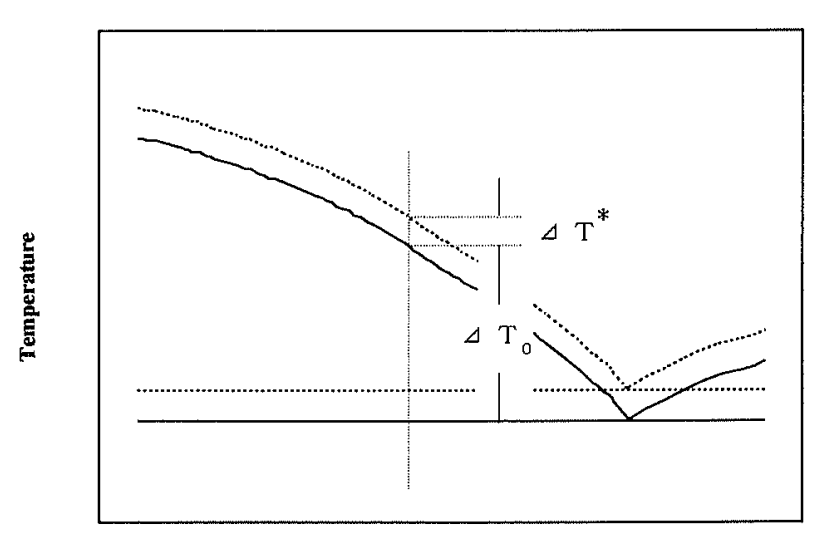

Enriched melt

(Fe-C-X system, $\mathrm{X}=\mathrm{Mn}, \mathrm{Si}, \cdots)$
Fig. 4.

Interpretation on supercooled solidification of pseudo-binary system of residual melt among steel dendrite arms. (solid line: supercooled state, dotted line: equilibrium state) 
$\Delta T_{0}$ is the difference between liquidus and solidus of the pseudo-binary system, i.e., $T_{\mathrm{ppt}}-T_{\mathrm{c}}$. Other values in Table 2 are given by the literatures cited. Then Eq. (4) gives a simple function of thermal Péclet number $\left(P_{t}\right)$,

$$
r=4.3 \times 10^{-11} / P_{\mathrm{t}}
$$

$P_{\mathrm{t}}$ is replaced by using Eq. (2), and then Eq. (6) is obtained,

$$
V r^{2}=320 \quad\left(\mu \mathrm{m}^{3} / \mathrm{s}\right)
$$

Now from Eq. (6) tip radius of dendritic Type II $\mathrm{MnS}$ can be calculated if growth rate is given. However, in supercooling solidification of inclusions as in the present case, growth rate of dendrite tip of inclusions is unable to be observed. Only calculation method like Lipton et $a l^{3)}$ did, or some other experimental method under a certain premises might give the growth rate. ${ }^{17)}$ The authors took a different way to calculate the growth rate with aid of observations as follows.

The size of a pool of enriched residual melt where sulfide-inclusions precipitate is calculated as explained in Sec. 2.1 , provided the site of the pool correspond to the edge of 14-facet polyhedron, and the shape of melt pool be approximated by a sphere, which is supported by the observations (see Fig. 4 in Ref. 12)). Let the radius of the sphere be $\zeta$, and the fraction of solid at the moment when sulfide starts precipitating be $f$, then we have a following relation,

$$
\begin{aligned}
& 6 \times(4 \pi / 3) \zeta^{3}=(1-f) V_{\mathrm{SuC}} \\
&=2.7 \times 10^{9}(1-f) R^{-0.14} G^{-0.5}, \\
& {\left[\zeta: \mu \mathrm{m}, V_{\text {SUC }}: \mu \mathrm{m}^{3}, R: \mu \mathrm{m} / \mathrm{s}, G:{ }^{\circ} \mathrm{C} / \mathrm{mm}\right] }
\end{aligned}
$$

where $V_{\text {SUC }}$ is volume of a 14-facet polyhedron, and is given as $V_{\text {SUC }}=2.7 \times 10^{9} R^{-0.14} G^{-0.5}$ (Ref. 12)). On the other hand, cooling rate of the pool of residual melt $(v)$ shall be given as $v=R G$, assuming the cooling rate is equal to that of the surrouding steel matrix. Then the time during which the pool is cooled from $T_{\mathrm{ppt}}$ to $T_{\mathrm{e}}$, or by $\Delta T_{0}$, is given as $\Delta T_{0} / v$.

If sulfide inclusion starts precipitating somewhere at a point on the inside of sphere and continues to grow from the point to the opposite side of the sphere, that means the traverse distance is $2 \zeta$, then the average growth rate of the sulfide-inclusion $\left(V_{\mathrm{cal}}\right)$ is estimated as,

$$
V_{\text {cal }}=2 \zeta /\left(\Delta T_{0} / v\right)
$$

The value of $V_{\text {cal }}$ for each test in Table 1 are given in Table 3. The results of observation on $\mathrm{MnS}$-diameter $\left(d_{\mathrm{MnS}}\right)$ are shown in Table 3 . Now the tip radius of MnS-inclusion ( $r$ ) can be calculated by Eq. (6), inserting $V_{\text {cal }}$ into $V$. The calculated $r$ value of each test is given in Table 3. In the calculation $f=0.99$ is used from the result of experiments. ${ }^{12)}$

The ratio of $r /\left(d_{\mathrm{MnS}} / 2\right)$ in Table 3 will indicate shapes near the tip of the primary arm of inclusions. By referring to the literatures ${ }^{7)}$ on the relationship between composition of steel and morphology of manganese-sulfide, the MnS-inclusion in the experiments should be in dendritic Type II or Type III. The observation ${ }^{12)}$ shows that the manganese-sulfides take themselves transient

Table 3. $v$ - and $\zeta$-value calculated with Eq. (7), $V_{\text {cal }}$ with Eq. (8) and $r$ with Eq. (6). $f=0.99$.

Stee la: $0.62 \mathrm{C}-0.12 \mathrm{Si}-0.58 \mathrm{Mn}-0.006 \mathrm{P}-0.073 \mathrm{~S}-$ $0.049 \mathrm{Al}-0.00110$

Stee lb: $0.52 \mathrm{C}-0.10 \mathrm{Si}-0.56 \mathrm{Mn}-0.003 \mathrm{P} \cdots 0.046 \mathrm{~S}$ $-0.037 \mathrm{Al}-0.001 \mathrm{IO}$

\begin{tabular}{rccccccc}
\hline $\begin{array}{c}\text { Rod } \\
\text { Test }\end{array}$ & Steel & $\begin{array}{c}v \\
(\mathrm{~K} / \mathrm{s})\end{array}$ & $\begin{array}{c}\zeta \\
(\mu \mathrm{m})\end{array}$ & $\begin{array}{c}\text { diameter } \\
d_{\text {Mns }} \\
(\mu \mathrm{m})\end{array}$ & $\begin{array}{c}V_{\text {cal }} \\
(\mu \mathrm{m} / \mathrm{s})\end{array}$ & $\begin{array}{c}r \\
(\mu \mathrm{m})\end{array}$ & $r /\left(d_{\text {Mns }} / 2\right)$ \\
\hline 9 & & & & & & \\
\hline 5 & $\mathrm{a}$ & 57 & 48 & 7.8 & 55 & 2.4 & 0.61 \\
3 & $\mathrm{a}$ & 140 & 42 & 6.8 & 84 & 2.0 & 0.59 \\
11 & $\mathrm{a}$ & 360 & 18 & 4.2 & 130 & 1.6 & 0.76 \\
12 & $\mathrm{~b}$ & 11 & 55 & 9.4 & 12 & 5.2 & 1.1 \\
13 & $\mathrm{~b}$ & 24 & 40 & 8.0 & 19 & 4.1 & 1.0 \\
17 & $\mathrm{~b}$ & 45 & 28 & 5.6 & 25 & 3.6 & 1.3 \\
\hline
\end{tabular}

$\mathrm{r} \sim \frac{1}{2} \mathrm{~d}_{\mathrm{MnS}}$

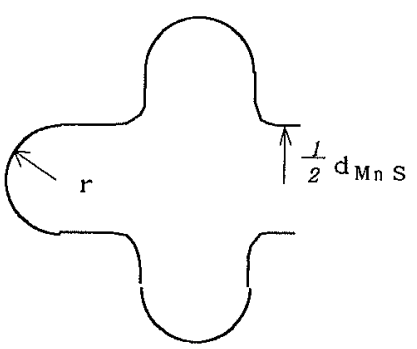

Fig. 5. $\quad r /\left(d_{\mathrm{MnS}} / 2\right)$-ratio and shape of $\mathrm{MnS}$-dendrite tip.

morphology of dendritic Type II or skeleton-like Type II/III. ${ }^{12)}$ The calculated ratios in Table 3 fairly correspond to the observation, viz., the primary arm of inclusion has nearly equal or a little larger tip radius than that of its arms. The meaning of 'the ratio $\sim 1$ ' in real shape of manganese-sulfide inclusions could be interpreted with the illustrations in Fig. 5.

\section{Consideration}

The purpose of the present work is applying a concept of dendritic solidification to manganese-sulfide inclusion in a pool of enriched residual melt which is gradually cooled. The idea proposed in this paper could be extended to most inclusions exhibiting dendritic morphology; dendritic alumina-silicate in Al-Si-killed steel, or aluminum-nitride precipitating in center segregation in strand cast slabs of nitride-treated steel. In any case the important would be to discern the solute whose partition between primary phase and enriched remnant melt of the concerned residual melt pool plays the decisive role in dendritic solidification of the primary phase which turns to inclusion.

Meanwhile, the idea gives another understanding on precipitation of inclusions, that is, we had better think the precipitation of dendritic inclusions in steel as a result of solidification of supercooled melt of the composition of inclusion, than as a result of nucleation and growth of a pure solid (inclusion) phase directly in the enriched melt. As well known, the nucleation and growth 


\section{Diffusion growth after nucleation}

$\mathrm{r}>\mathrm{r}_{0}($ critical size), spherical

growth occurs,

\section{Marginal stability}

Only stable $\mathbf{r}$ can continue to propagate, in the preferred direction of crystalline nature of pure extreme phase of inclusions
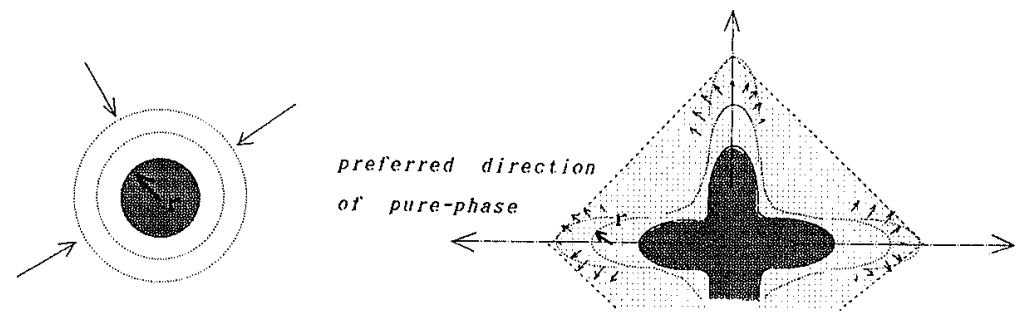

arrows indicating the gathering of constituent elements which forms inclusions

arrows indicating diffusion of solute which tends to be excluded from inclusions

Fig. 6. Difference between nucleation and growth theory and marginal stability theory.

theory is applicable to initiating stage of growth, therefore we have to look for another interpretation why the inclusions take dendritic morphology. Furthermore, it is absolutely impossible to give any explanation why sulfide inclusions change their morphology from Type II to Type III depending on increase in the ratio of $\mathrm{MnS} /(\mathrm{MnS}+\mathrm{FeS})$ of manganese-sulfide inclusions. The coincidence between the morphology change and the ratio is unabale to be accepted without admitting the existence of melt of the same composition as that of the inclusion which is going to precipitate. In another words, a liquid phase region whose chemical composition approaches to that of inclusion, appears in the enriched melt prior to the precipitation. The region shall be defined with obscure interface forming the contour of final shape of inclusion, and then the liquid $\rightarrow$ solid transformation occurs, which we call precipitation. Figure 6 shows the idea.

In applying the solidification theory, however, attention should also be paid to the morphology transition rule of inclusions. As previously mentioned, Steinmetz and Lindenberg ${ }^{6-8)}$ proposed a regularity on morphology change of inclusions depending upon the activity balance of the constituent elements. The meaning of the regularity might be interpreted from another point of view, viz., a relation of magnitude between the free energy of interface and the formation energy of inclusions. The former is, ordinarily, indicated with $\sigma$, which is defined as interfacial free energy per unit volume and is given as $\Gamma \cdot \Delta S, \Delta S$ being difference in entropy between liquid and solid. And the latter, with $\Delta H$. Both can be used in calculating with Eq. (1). If $\sigma$ is high enough compared with $\Delta H$, i.e., interfacial energy plays the crucial role in determining the shape of inclusions. The shape will simply be sphere, if we do not apply any other different metallurgical concept than the classical nucleation and diffusional growth. This type of sulfide-inclusion is well known as Type I which, in fact, is an eutectic phase of oxy-sulfides of manganese, and has small $\Delta T_{0}$.

Manganese-sulfide in low/middle carbon killed-steels exhibits eutectic or dendritic morphology, which means $\sigma$ could not behave as the decisive factor in determining the shape of the inclusion, but the magnitude of $\Delta H$, i.e., crystalline nature would influence to the morphology. In these cases $\Delta T_{0}$ should be a moderate magnitude to allow eutectic or dendritic growth. The chemical state of such melt system could be characterized as 'moderate activity balance of the constituent elements' as Steinmetz and Lindenberg have shown. (Referred to the implicative drawings ${ }^{6,7)}$ by them). And, if primary phase approaches the compound of pure extreme, which has ordinarily larger formation energy than that of eutectic phase, which can be expressed as if primary phase has higher $\Delta T_{0}$, the morphology of inclusion would be determined by the crystalline system of the inclusion', and in this case the activities of the constituent elements approach to unity in the melt (See the drawings ${ }^{6,7)}$ ). Since $\mathrm{MnS}$ with higher purity as inclusion in steel belongs to cubic crystalline system, the MnS-inclusion grows with octahedral morphology, which is called Type III. It should be noted so-called 'skeleton-like Type II-MnS' is one derivative of the octahedral, which simply failed in growing to the right octahedral shape. Figure 7 shows the morphology transition from the viewpoint of free energy balance between $\sigma$ (interfacial free energy) and $\Delta H$ (formation energy).

The transition of skeleton-like Type II to Type III could be understood as follows. In residual melt in which the manganese-sulfide liquid region is insufficiently enriched, the liquid phase is unable to transform to solid state of pure $\mathrm{MnS}$, without reduction of the volume, since other atoms than $\mathrm{Mn}$ and $\mathrm{S}$, in particular $\mathrm{Fe}$ and $\mathrm{C}$, must be ejected from the region into the remnent melt. The reduction of volume does not mean equi-axed contraction, but formation of dendritic skeleton. On the other hand in the residual melt of high carbon/alloyed steel, it is thought manganese-sulfide liquid region is already sufficiently enriched to be able to precipitate as pure $\mathrm{MnS}$ at the precipitation start, and solidifies easily without any significant reduction of volume, since in the steel the liquidus-solidus range of residual melt $\left(\Delta T_{0}\right)$ is large enough. The authors arbitrarily anticipate that the liquid region might take contour of octahedral 

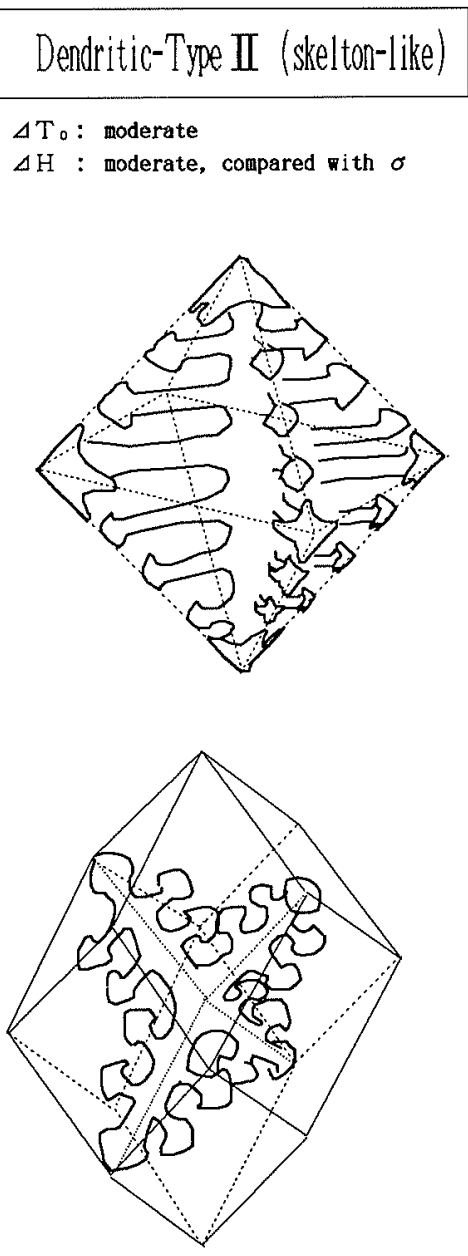

Dendritic-alumina

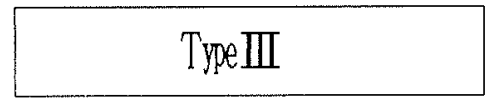

$\Delta \mathrm{T}_{0}:$ large

$\Delta \mathrm{H}$ : high, compared with $\sigma$
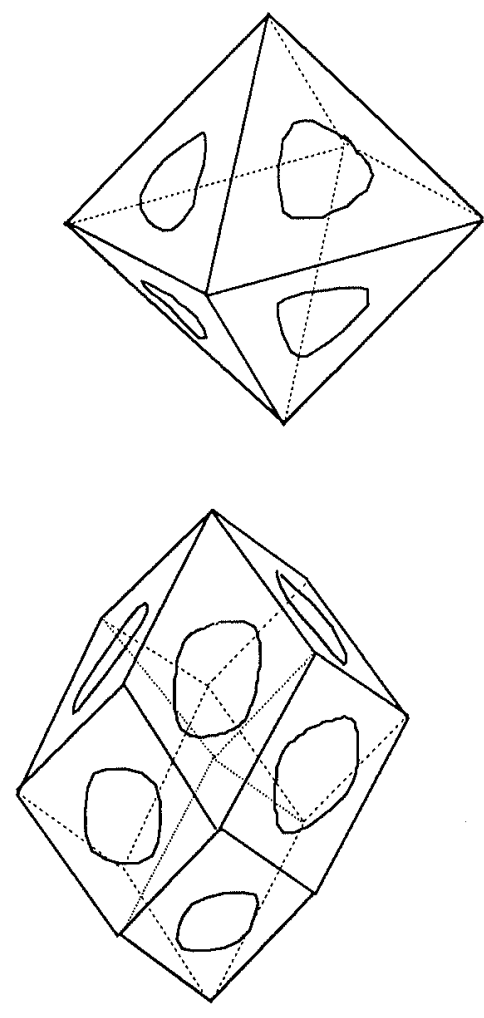

corundum
Fig. 7.

Morphology transition of manganese-sulfide; dendritic-Type II (skeleton-like) to Type III. morphology or its irregular derivative shape from the result of observation (Ref. 12)). Figure 7 can be understood as an interpretation of these ideas.

Based on the idea explained above, dendritic nature of dendritic inclusions should be considered with crystalline system of the pure extreme phase. Aluminumoxide in steel, which has corundum phase $\left(\alpha-\mathrm{Al}_{2} \mathrm{O}_{3}\right)$ as the pure extreme, belongs to rhombic, therefore tends to grow pervading rhombic 12-facet polyhedron (Fig. 8), when activity of aluminum in steel is high. In low activity of aluminum, the oxide takes dendritic morphology which, however, grows in slant directions, not in orthogonal one as manganese-sulfide does. The generallized idea on morphology transition proposed by Steinmetz and Lindenberg ${ }^{6,7)}$ could be interpreted with the idea which the present authors propose.

\section{Conclusion}

The authors examined if the modern solidification theory is applicable to dendritic inclusions in steel, and gave a clue to its capability to estimate the radius of dendritic Type II manganese-sulfide inclusion. The method used is Liptons' theory which is derived from the marginal stability criterion. In applying the theory, it is shown that following way of thinking is important; i.e., manganese-sulfide precipitates in a pool of residual melt which lost continuity to the mass of melt. Hence the precipitation is regarded as supercooling solidification of manganese-sulfide phase in the enriched pool of residual melt. In another words, the two phases; phase of inclusion and remnant phase of enriched pool of residual melt, should be regarded to compose a pseudobinary system, and precipitation of dendritic inclusions can be treated as dendritic solidification of primary phase (inclusion) under small supercooling. Carbon plays the role of solute which determines the interface, and the temperature range of solidification $\left(\Delta T_{0}\right)$ is taken as the difference between temperature of start of precipitation and that of finish of solidifying of the residual melt.

Since the result of calculation is coherent to the data observed, it is concluded the concept of marginal stability, or perturbation theory, can be applied to the precipitation of dendritic inclusions in steel. And, another understanding is proposed on precipitation kinetics of dendritic inclusions; i.e., formation of dendritic morphology of the inclusions is determined, not by the diffusion growth mechanism of pure inclusions after nucleation, but by the preferred perturbation wave length of interface between inclusion and enriched remnant melt of residual melt, viz., by marginal stability mechanism. Further insight into this kinetics leads to the idea that liquid phase of dendritic inclusions prior to start of pre- 
cipitation has an inclination of taking a contour of polyhedron-like shape which the phase of pure inclusion would take. The idea has an advantage in understanding the behavior of morphology transition which has been reported as a relationship between morphology of inclusions and activities of the constituent elements in local melt where inclusions precipitate.

\section{Acknowledgments}

The authors would like to thank Professor T. Umeda and Professor T. Suzuki of The University of Tokyo for discussions on the theoretical aspect of the present research

\section{Nomenclature}

$r:$ radius of dendrite-tip of inclusions

$V$ : growth velocity of dendrite tip of inclusions

$V_{\text {cal }}$ : calculated value of $V$

$T_{\mathrm{S}}$ : equilibrium solidus of steel

$T_{\mathrm{LS}}$ : solidus of steel at a given solidification (cooling) condition

$T_{\mathrm{L}}$ : equilibrium liquidus of steel

$T_{\mathrm{L}}^{*}$ : supercooled liquidus at steel-dendrite tip; $T_{\mathrm{L}}^{*}=T_{\mathrm{L}}-\Delta T^{*}$

$\Delta T^{*}: \quad$ supercooling at dendrite tip

$\Delta T_{0}$ : liquidus-solidus range of a binary system

$T_{\mathrm{e}}$ : solidifying temperature of residual melt pool or eutectic temperature of residual melt pool

$\Gamma$ : Gibbs-Thompson parameter of inclusion/residual-melt interface

$\sigma^{*}$ : stability constant for stable inclusion-dendrite tip, details in Refs. 4), 5)

$P$ : $\quad$ solute Péclet number for inclusion-dendrite tip; $V r / 2 D$

$P_{\mathrm{t}}: \quad$ thermal Péclet number; $V r / 2 a_{\mathrm{t}}$

$D$ : diffusion coefficient of solute (carbon)

$k$ : equilibrium partitition coefficient of solute between solid/liquid

$a_{\mathrm{L}}$ : thermal diffusivity of liquid

$c_{\mathrm{L}}$ : volumetric specific heat of liquid

$\Delta H$ : latent heat of fusion of inclusion per uint vilume

$\beta: \quad 0.5\left\{1+\left(K_{\mathrm{S}} / K_{\mathrm{L}}\right)\right\}$

$k_{\mathrm{S}}$ : thermal conductivity of solid

$K_{\mathrm{L}}$ : thermal conductivity of liquid

$\xi_{\mathrm{s}}$ : function of thermal Péclet number (solid), details in Ref. 5)
$\xi_{L}$ : function of thermal Péclet number (liquid), details in Ref. 5)

$I_{\mathrm{V}}(P)$ : Ivantsov function of $P$, details in Refs. 5), 15)

$R$ : growth rate of primary dendrite tip of steel

$G$ : temperature gradient around primary dendrite tip of steel

$v$ : cooling rate of residual melt

$\zeta$ : radius of isolated residual melt-pool among steel dendrite arms

\section{REFERENCES}

1) J. S. Langer and H. Müller-Krumbhaar: J. Cryst. Growth, 42 (1977), 11.

2) W. Kurz and D. J. Fisher: Acta Metall, 29 (1981), 11.

3) J. Lipton, M. E. Glicksman and W. Kurz: Metall. Trans., 18A (1987), 341 .

4) J. S. Langer and H. Müller-Krumbhaar: Acta Metall., 26 (1978), 1681

5) R. Trivedi and W. Kurz: Int. Mat. Rev., 39 (1994), 49

6) E. Steinmetz and H. U. Lindenberg: Arch. Eisenhüttenwes., 47 (1976), 199.

7) E. Steinmetz and H. U. Lindenberg: Arch. Eisenhüttenwes., 47 (1976), 521 .

8) E. Steinmetz and H. U. Lindenberg: Arch. Eisenhüttenwes., 47 (1976), 713.

9) Y. Ito, N. Masumitsu and K. Matsubara: Tetsu-to-Hagané, 66 (1980), 647.

10) Y. Ueshima, Y. Sawada, S. Mizoguchi and H. Kajioka: Metall. Trans., 20A (1989), 1375.

11) K. Oikawa, H. Ohtani, K. Ishida and T. Nishizawa: ISIJ Int., 35 (1995), 402.

12) M. Imagumbai: ISIJ Int., 34 (1994), 896.

13) M. Imagumbai: ISIJ Int., 34 (1994), 992.

14) J. Lipton, W. Kurz and R. Trivedi; Acta Metall, 35 (1987), 957.

15) G. P. Ivantsov: Dokl. Akad. Nauk. SSSR, 58 (1947), 567.

16) S.-C. Huang and M. E. Glicksman: Acta Metall., 29 (1981), 701.

17) T. Suzuki and K. Sakuma: ISIJ Int, 35 (1995), 178.

18) W. Dahl, H. Hengstenberg and C. Düren: Stahl Eisen, 86 (1966), 782.

19) T. J. Baker and J. A. Charles: JISI, (1972), Sep., 702.

20) L. K. Bigelow and M. C. Flemings: Metall. Trans., 6B (1975), 275.

21) E. Schürmann: Giesserei, 48 (1961), 481.

22) N. Sano, M. Iwata, H. Hosoda and Y. Matsushita: Tetsu-toHagané, 57 (197I), 1984.

23) M. Fischer: Dissertation, Tech. Univ. Clausthal, (1977).

24) M. Fischer and K. Schwerdtfeger: Metall. Trans., 8B (1977), 467

25) Handbook for Molten-Iron and Melt Steel, ed. by ISIJ, ISIJ, Tokyo, (1971).

26) J. F. Elliott, M. C. Gleiser and V. Ramakrishna: Thermochemistry For Steelmaking, Pergamon Press, New York, (1963), 702. 